\title{
VERDADE COMO CONDIÇÃO DE (IM)POSSIBILIDADE PARA A (IN)VISIBILIDADE DA E NA ADMINISTRAÇÃO PÚBLICA
}

\section{TRUTH AS THE CONDITION FOR THE (IM)POSSIBILITY OF (IN)VISIBILITY OF AND IN PUBLIC ADMINISTRATION}

\author{
PATRÍCIA MAINO WARTHA ${ }^{1}$
}

\begin{abstract}
RESUMO: Ao se preconizar transparência na e da Administração Pública, não se quer dizer apenas que todas as pautas sejam noticiadas, o que se almeja de fato é que informações úteis e "verdadeiras" alcancem a quem realmente interessa, ou seja, encontrem seus legítimos destinatários. Todavia, discute-se quanto à viabilidade do encontro da verdade, ou seria a veracidade o único instrumento possível de ser concretizado.
\end{abstract}

PALAVRAS-CHAVE: Verdade; Veracidade; Visibilidade; Transparência; Publicidade.

ABSTRACT: In recommending whether and transparency in public administration, not to say only that all tariffs are reported, which aims fact is that useful information and "real" reach those who really matter, ie, find its rightful recipients. However, we discuss about the feasibility of meeting the truth or the truth would be the only means possible to achieve.

KEYWORDS: Truth; Accuracy; Visibility; Transparency; Publicity.

SUMÁRIO: 1. (In)visibilidade e Publicidade; 2. Veracidade ou Verdade como Pressuposto de Visibilidade; 3. Caso Concreto, Verdade e/ou Realidade; Referências Bibliográficas.

SUMMARY: 1. (In)Visibility and Publicity, 2. Veracity or Truth as a Condition of Visibility; 3. If Concrete, Real and/or Reality; References.

\footnotetext{
Artigo recebido em 18.04.2011. Pareceres emitidos em 23.05.2011 e 01.08.2011.

Artigo aceito para publicação em 13.08.2012.

${ }^{1}$ Graduada em Direito pela Universidade de Caxias do Sul. Mestre em Direito Público pela UNISINOS (2010). Advogada. Professora de Ensino Superior e Coordenadora do Núcleo de Práticas Jurídicas do Centro de Ensino Superior Cenecista de Farroupilha. Integrante do Núcleo Docente Estruturante da mesma instituição e Doutoranda em Qualidade Ambiental pela Universidade Feevale.advpatriciamw@gmail.com ou ajucesf@cesfar.com.br
} 


\section{1. (IN)VISIBILIDADE E PUBLICIDADE}

Imensamente equivocada é a proposição de um Estado Democrático de Direito, e de uma Administração Pública transparente, se o que se torna visível são fatos e informações falsas ou inverídicas. ${ }^{2}$

A transparência da Administração Pública não se efetiva com a mera publicidade de informações, haja vista que, se os dados publicizados não imprimem a realidade, equivocado se torna tratar de visibilidade e transparência, o mais adequado seria a denominação de aparência.

A imagem, a aparência, nem sempre correspondem à realidade, uma vez que nem tudo que é tornado visível é verdadeiro. Observe-se os instrumentos midiáticos e sua tarefa de tornar visível tudo e todos, ultrapassando as barreiras do espaço e do tempo e da fidelidade dos próprios fatos reais noticiados.

Assim sendo, ao se falar de um Estado visível, que tem como pressuposto uma Administração Pública transparente, não se quer dizer apenas que todas as pautas sejam noticiadas, o que se almeja de fato é que informações úteis e "verdadeiras" alcancem a quem realmente interessa, ou seja, encontrem seus legítimos destinatários. Isso não se refere apenas à Administração Pública como a toda a sociedade, haja vista que não apenas as pessoas públicas têm o dever de verdade e impessoalidade, os indivíduos que compõem a coletividade também devem preservar e exercitar tais atributos.

\section{VERACIDADE OU VERDADE COMO PRESSUPOSTO DE VISIBILIDADE?}

A verdade ${ }^{3}$ como pressuposto de visibilidade não deveria representar uma expectativa e sim uma obrigatoriedade, haja vista representar condição de possibilidade à publicização de informação socialmente útil.

Gadamer profere que "verdade é desocultação" revelando que o sentido do discurso "é deixar e fazer com que o desocultado se apresente, se revele".

\footnotetext{
${ }^{2}$ Para que a informação se considere um direito fundamental, Castanho de Carvalho aponta como um dos pressupostos a verdade. In: CARVALHO, Luiz Gustavo Grandinetti Castanho de. Liberdade de Informação e o Direito Difuso à Informação Verdadeira. 2. ed., Rio de Janeiro: Renovar, 2003. p. 142.

${ }^{3}$ Nesse liame, Pontes de Miranda discorre que "o que se há de pôr em primeiro lugar é o direito à verdade". In: MIRANDA, Pontes de. Liberdade de Imprensa e Censura. In: BONAVIDES, Paulo. ET AL. As Tendências Atuais do Direito Público: Estudos em homenagem ao professor Alfonso Arinos de Melo Franco. 1. ed., Rio de Janeiro: Forense, 1976. p. 185.

${ }^{4}$ GADAMER, Hans-Georg. Verdade e Método II: complementos e índice. Petrópolis, RJ: Vozes, 2002. Tradução de Ênio Paulo Giachini. p. 60. Gadamer entrelaçando verdade e desocultamento refere que "Ao recuperar o sentido da palavra grega que designa a verdade, Heidegger possibilitou em nossa geração um conhecimento promissor. Não foi Heidegger o primeiro a descobrir que Aletheia, significa propriamente desocultação (Unverborgenheit). Heidegger nos ensinou o que significa para o pensamento de ser o fato de a verdade precisar ser arrebatada da ocultação (Verborgenheit) e do velamento (Verhohlenheit) das coisas como um roubo. A ocultação e o velamento pertencem ao mesmo fenômeno. As coisas mantêm-se por si próprias em estado de ocultação; 'a natureza ama esconder-se', teria dito Heráclito. Mas também o velamento pertence à ação e ao falar próprios dos seres humanos, pois o discurso humano não
} 
Observa-se, pois, que para a obtenção de um Estado Democrático de Direito visível é imprescindível a desocultação, o desvelamento, especialmente no cenário brasileiro que se mostra opaco e que nos raros instantes em que disponibilizam informações à população, o faz de forma interessada, manipulando a notícia em benefício particular. Isso fere o princípio da transparência e desvirtua o princípio da publicidade que deveria resultar em Estado e Administração visíveis se preservasse a impessoalidade e abarcasse somente a verdade.

Surge nesse âmbito a discussão a cerca da verdade ${ }^{5}$, ou será veracidade. Reafirmando a dicotomia existente entre verdade e veracidade encontra-se Têmis Limberger que reflete sobre o tema afirmando que "Informação veraz não é sinônimo de informação verdadeira", justificando tal assertiva na medida em que aponta construção jurisprudencial no sentido de que "a informação veraz é aquela que contou com a diligência do comunicador". ${ }^{\circ}$

A verdade é desprovida de quaisquer acréscimos do informador, o relato deve fidelizar unicamente à realidade. Diferentemente, a veracidade traz consigo aditivos subjetivos peculiares a cada um dos transmitentes da informação, o que não quer de forma alguma dizer que a veracidade corresponda à mentira.

Ao passo que a mentira é uma intencional distorção dos fatos, a veracidade consiste em uma narrativa pessoal dos acontecimentos, de modo a viciar a realidade de subjetivismo embora preserve a essência do ocorrido. ${ }^{7}$

transmite apenas a verdade, mas conhece também a aparência, o engano e a simulação. Há um nexo originário, portanto, entre ser verdadeiro e discurso verdadeiro. A desocultação do ente vem à fala no desvelamento da proposição." GADAMER, Hans-Georg. Verdade e Método II: complementos e índice. Petrópolis, RJ: Vozes, 2002. Tradução de Ênio Paulo Giachini. p. 59-60. Frize-se ainda que para Gadamer a verdade do discurso é determinada pela adequação do discurso à coisa p. 61.

${ }^{5}$ Torna-se bastante delicado tratar sobre verdade, já que embora se trate a verdade como algo próximo e presente, talvez nunca será descoberta a sua essência originária. Assim reflete Nietzsche em Verdade e Mentira no sentido extra-moral: "No momento em que aprende a questionar a si mesma, a verdade talvez termine por revelar alguma não-verdade à sua base, prestando um testemunho inteiramente inesperado sobre si própria". (p. 9-10). Ao se imaginar saber algo a respeito das coisas, o que se tem são simplesmente metáforas dessas coisas, o que não corresponde a sua essência. (p.15 e 33-34). Para Nietzsche o que se tem são ilusões e não verdades. (p. 37). “(...) a compreensão essencialista da linguagem, revela-se, desde logo, uma fonte inesgotável de auto-enganos. (...) condicionando o homem ao hábito gramatical de interpretar a realidade (...)". (p. 16-17). Nietzsche combate a idéia de que seja possível a obtenção, através das palavras, "ao núcleo indivisível e inquestionável do existir. A seu ver, a verdade que as palavras nos colocariam em mãos seria de ordem tautológica. Através delas, o homem apenas reencontraria aquilo que ele próprio teria introduzido nas designações.". (p. 17 e 40). In: NIETZSCHE, Friedrich. Sobre Verdade e Mentira. Fernando de Moraes Barros (Org. e Trad.) São Paulo: Hedra, 2007.

${ }^{6}$ LIMBERGER, Têmis. O Direito à Intimidade na Era da Informática: A necessidade de proteção dos dados pessoais. Porto Alegre: Livraria do Advogado, 2007. p. 133.

${ }^{7}$ Divergindo quanto à veracidade, Nietzsche refere que é uma condição de existir da sociedade, a qual consiste na "obrigação de mentir conforme uma convenção consolidada, mentir em rebanho num estilo a todos obrigatório." In: NIETZSCHE, Friedrich. Sobre Verdade e Mentira. Fernando de Moraes Barros (Org. e Trad.) São Paulo: Hedra, 2007. p. 37. 
Acentuando a necessidade de verdade, Peter Häberle discorre que a verdade é um valor cultural irrenunciável do Estado Constitucional, um objeto de domínio público. Sob essa perspectiva um Estado jamais poderia se fundar em verdades absolutas, pré-estabelecidas, parciais, e, portanto, verazes, uma vez que a verdade necessita ser buscada para ser revelada, e que essa "eterna busca pela verdade" é possível partindo-se das três verdades fundamentais do Estado Constitucional: liberdade do culto religioso, da arte e da ciência. ${ }^{8}$

Para tanto, prevê que todo Estado Constitucional deve defender um direito à verdade e para isso devem ser evitadas e punidas as não verdades, além de preservar-se a transparência e a imparcialidade, uma vez que as classifica como condições para a busca da verdade.

O que se verifica é que a veracidade tem acolhida na sociedade atual, mas o que se torna realmente preocupante é a falta de diligência dessas informações consideradas verazes, o que acarreta em admissão de inveracidades. Nesse sentido, é observada a banalização da verdade à proporção que a mentira ao invés de ser repelida é tida como corriqueira.

Em não se investigando, ou minimamente averiguando a notícia, se está legitimando a falácia, dessa forma, a inquietude se torna uma das formas de busca pela verdade.

A cautela é indubitável no que diz respeito à verdade da informação já que múltiplos são os comunicadores e diversos são os receptores, sendo que a notícia mentirosa, ao se alastrar pode desestruturar toda a sociedade, uma vez que elimina a própria realidade.

A esse respeito Menéndez afirma que "(...) la veracidad de la información a la que alude el precepto constitucional no quiere decir que solo pueda recibirse información que sea veraz". Estabelecendo proteção aos que recebem informação falsa, na medida em que não há como impedir que isso ocorra. "La veracidad no es un límite del ámbito del derecho a recibir información, ofreciendo garantía constitucional sólo a la recepción de aquello que sea veraz, sino una cualidad que delimita el concepto da información(...)". ${ }^{9}$ Propõe, para tanto, a articulação legal à proteção do receptor de falsa notícia, passando assim a ser exigida a verdade da informação ao seu emissor.

Observe-se que, mesmo estando Menéndez se referindo à realidade espanhola, tais dados perfeitamente se encaixam ao perfil brasileiro.

Desta monta, considera-se perturbadora do processo de comunicação pública não apenas a transmissão de informação falsa, bem como qualquer tipo de deformação à mesma que pretenda enganar o receptor.

\footnotetext{
${ }^{8}$ HÄBERLE, Peter. Verdad y Estado Constitucional. 1. ed., México. D.F.: Instituto de Investigaciones Jurídicas, 2006. p. 119-120, 124 e 139. Peter Haberle trata ainda a verdade como conceito vinculante para a liberdade, justiça e bem estar do Estado Constitucional, e que a Justiça é a verdade do Direito. p. 142 e 151.

${ }^{9}$ MENÉNDEZ, Ignácio Villaverde. Los Derechos Del Público: El derecho a recibir información del artículo 20.1.d) de la Constitución Española de 1978. Madrid: Editorial Tecnos S.A., 1995. p. 78.
} 
O estudioso também concorda que verdade e veracidade não são sinônimos. ${ }^{10}$ À verdade atribui-se o significado de realidade, ao passo que a veracidade é uma espécie de correspondência do que se diz com quem o diz. Em consequência, enquanto o contrário da verdade ou dos diversos tipos de verdade, é o erro, o contrário da veracidade é a mentira ou o engano. Nesse viés, a veracidade poderia se equivaler à sinceridade. ${ }^{11}$

Diante do exposto, e frente à impossibilidade de se lançar definições conclusivas e absolutas, o que se torna possível constatar é que a veracidade é eivada de moralidade, de pessoalidade, enquanto a verdade permanece inerte ao passo que simplesmente se reporta à realidade.

É conveniente ainda fazer um breve aporte a cerca de verdade real e formal $^{12}$ mesmo que tal classificação ou distinção pareça superada.

Utilizada processualmente, essa distinção entre verdade real e formal, era tida como premissa básica. A expressão quod non est in actis non est in mundo que significa "o que não está nos autos não está no mundo" define a verdade formal, distinguindo-se da verdade real que é a que pertence ao mundo, não ao processo exclusivamente.

\footnotetext{
${ }^{10}$ MENÉNDEZ, Ignácio Villaverde. Los Derechos Del Público: El derecho a recibir información del artículo 20.1.d) de la Constitución Española de 1978. Madrid: Editorial Tecnos S.A., 1995. p. 79.

${ }^{11}$ A respeito de verdade e veracidade tem-se considerado muitas vezes que a veracidade equivale à sinceridade, o que parece indicar que é possível ser veraz e não dizer a verdade, todavia, não parece possível ser veraz sem vontade de dizer a verdade. Por isso não se pode ser veraz mentindo, como também se não pode sê-lo mantendo uma atitude de indiferença, ou de despreocupação, pela verdade. Assim, é possível entender que a veracidade é uma verdade para consigo mesmo já que a essência da "veracidade" se encontra na relação pessoal.

${ }^{12}$ Antigamente a distinção entre verdade real e formal, ou formal e substancial, era atribuída ao processo penal e ao civil, sob a justificativa de que o processo penal lidava com a liberdade do indivíduo pressupondo por isso de uma verdade real. Todavia, questiona-se, mas os pleitos de processo civil não lidam também com indivíduos e seus direitos? Desta monta, estudiosos como Marinoni, afirmam que atualmente, a distinção entre verdade formal e substancial perdeu seu brilho. A doutrina moderna do direito processual vem sistematicamente rechaçando esta diferenciação, corretamente considerando que os interesses objeto da relação jurídica processual penal não têm particularidade nenhuma que autorize a inferência de que se deve aplicar a este método de reconstrução dos fatos diverso daquele adotado pelo processo civil. Realmente, se o processo penal lida com a liberdade do indivíduo, não se pode esquecer que o processo civil labora também com interesses fundamentais da pessoa humana - como a família e a própria capacidade jurídica do indivíduo e os direitos metaindividuais - pelo que totalmente despropositada a distinção da cognição entre as áreas. [...] Também Carnelutti ofereceu semelhante crítica à figura, qualificando-a como verdadeira metáfora. Realmente, falar-se em verdade formal (especialmente em oposição à verdade substancial) implica reconhecer que a decisão judicial não é calcada na verdade, mas em uma não-verdade. Supõe-se que exista uma verdade mais perfeita (a verdade substancial) mas que, para a decisão no processo civil, deve o juiz contentar-se com aquela imperfeita e, portanto, não condizente com a verdade. A idéia de verdade formal é, portanto, absolutamente inconsistente e, por esta mesma razão, foi (e tende a ser cada vez mais), paulatinamente, perdendo seu prestígio no seio do processo civil. A doutrina mais moderna não propõe qualquer referência mais a este conceito, que não apresenta qualquer utilidade prática, sendo mero argumento retórico a sustentar a posição cômoda do juiz de inércia na reconstrução dos fatos e a freqüente dissonância do produto obtido no processo com a realidade fática. In: Marinoni, L. G.; Arenhart, S. A. Comentários ao Código de Processo Civil. 5 v. tomo 1. São Paulo: Revista dos Tribunais, 2000. p. 37.
} 
Sob essa ótica de distinção entre verdades formais e reais, o processo era tido como uma realidade a parte, fora ou separada da realidade mundana, o que deverás é inaceitável, haja vista o propósito da existência do Judiciário ser exatamente a resolução de casos concretos. Desta monta, aceitar tal distinção é renegar a verdade tanto no processo quanto no mundo.

Destarte, é inegável a complexidade em não apenas definir a verdade, como principalmente em obtê-la, frente à pessoalidade das relações, todavia, um fato é indiscutível, a verdade existe, por mais difícil que seja encontrá-la. ${ }^{13}$

\section{CASO CONCRETO, VERDADE EIOU REALIDADE}

Apesar da contemporaneidade não mais admitir mitos de verdades absolutas, ${ }^{14}$ isto porque não é possível atribuir o significado de verdade a premissas pré-concebidas, haja vista a necessidade de se considerar o caso concreto, além do conhecimento integral dos argumentos das partes, abrindo, desta monta, espaço para a aprendizagem, para o aprimoramento, para a adequação. O fato de não haver verdades prontas, no plano abstrato, não justifica a busca de soluções nas preferências éticas e políticas do julgador ou intérprete, ou seja, na discricionariedade, haja vista que todo o ordenamento carece de verdade, de realidade, devendo inadmitir-se qualquer distorção ou falsidade do fato concreto.

Frente à extrema dificuldade de conceituar verdade, o que parece mais sensato é tê-la como realidade ${ }^{15}$ isenta de acréscimos ou diminuições.

${ }^{13}$ Embora possa parecer até utópico a pressuposição de verdade, a realidade sabe-se é concreta, e a verdade não seria justamente o relato de realidade isento de quaisquer acréscimos? E não suficiente, sendo a veracidade uma versão da verdade, em se buscando versões de uma mesma realidade não se poderia alcançar a verdade? Sob essas reflexões revela-se plausível a busca pela verdade, pois a legitimidade da veracidade pode trazer superficialidade não apenas à Administração Pública, mas a todo o Estado Democrático de Direito. Em todas as contendas judiciais colidem a todo o instante as veracidades proferidas pelos litigantes, ocasião em que o juiz procura desvendar única e exclusivamente a verdade do caso para então proferir sua decisão. Streck, a respeito da busca pela verdade refere que: "- ou desistimos da verdade, considerando que o mundo é um vasto teatro em que as subjetividades se enfrentam e que o que importa é apenas a versão de quem ganha a luta (retórica ou armada), - ou então, talvez seja possível amparar a verdade, preservá-la de nossas próprias motivações". STRECK, Lenio Luiz. Verdade e Consenso: Constituição, Hermenêutica e Teorias Discursivas. Da Possibilidade à Necessidade de Respostas Corretas em Direito. 2. ed., Rio de Janeiro: Lúmen Júris Editora, 2008. p. 418.

${ }^{14}$ A repugnância a conceitos universalizantes é constatada por Laurence Tribe e Michael Dorf, referindo que grande parte das pessoas perderam a fé em verdades universais e inquestionáveis: "Grande parte das pessoas já perdeu a fé nas idéias de eterno, universal e verdade inquestionável. Mas de alguma forma, na sua maneira comum de viver, ainda conseguem distinguir entre o que parece um argumento bom e o que parece sofisma". Todavia, enfatizam que "é importante apresentar argumentos significativos em um mundo bombardeado com verdades de última hora". In: TRIBE, Laurence e Michael Dorf. Hermenêutica Constitucional. Belo Horizonte: Editora Del Rey Ltda., 2007. p. 18-19.

${ }^{15}$ Nesse sentido, Arend afirma que: "Conceitualmente, podemos chamar de verdade aquilo que não podemos modificar; metaforicamente, ela é o solo sobre o qual nos colocamos de pé, e o céu que se estende acima de nós". In: ARENDT, Hannah. Entre o Passado e o Futuro. Trad. Mauro W. Barbosa. 6. ed., São Paulo: Perspectiva, 2009. p. 325. 
E na medida em que a verdade emana credibilidade, segurança e legitimidade, e sua ausência reflete em medo, denota-se o poder intrínseco à verdade. Nesse aporte, Foucault propõe a existência de um vínculo ativo entre poder e verdade. ${ }^{16}$

Tanto é real esse vínculo entre verdade e poder que a própria mentira pode gerar poder, quando transpareça ser verdadeira.

Sob a ótica de Arendt a verdade distingue-se em factual e filosófica, ${ }^{17}$ problematizando, a esse respeito, a tentativa de transformar a imagem publicitária em sucedâneo da veracidade nos contemporâneos processos de manipulação das massas. Salienta que o mentiroso, como homem de ação, deseja transformar o mundo não a partir da realidade compartilhada por todos, mas à custa da veracidade e da destruição do solo sobre o qual se firma qualquer opinião e ação. Assevera, desta monta que a verdade factual, ou seja, a informação, não deve ser monopólio de quem age ou decide, mas de toda comunidade. Por isso, constata-se na obra arendtiana a ideia de que a esfera pública alimenta-se da veracidade das informações.

Ainda é interessante esclarecer o ponto de vista arendtiano a cerca da diferença entre segredo de Estado e mentira. No segredo, o Estado apenas classifica as informações que poderão vir a público, em contrapartida, na mentira o objetivo é a manipulação da população. Para a estudiosa, "A verdade possui uma força que lhe é própria e os homens de poder até

\footnotetext{
${ }^{16}$ Foucault explica que a verdade não existe fora do poder ou sem poder. Cada sociedade tem seu regime, sua política de verdade, definindo os tipos de discursos que ela faz funcionar como verdadeiros. A isso se associam mecanismos para distinguir os enunciados verdadeiros dos falsos, técnicas e procedimentos valorizados para se obter a verdade, e um estatuto aos que têm o encargo de dizer o verdadeiro: "Em nossas sociedades, a "economia política" da verdade tem cinco características historicamente importantes: a "verdade" é centrada na forma do discurso científico e nas instituições que o produzem; está submetida a uma constante incitação econômica e política (necessidade de verdade tanto para a produção econômica, quanto para o poder político); é objeto, de várias formas, de uma imensa difusão e de um imenso consumo (circula nos aparelhos de educação ou de informação, cuja extensão no corpo social é relativamente grande, não obstante algumas limitações rigorosas); é produzida e transmitida sob o controle, não exclusivo, mas dominante, de alguns grandes aparelhos políticos ou econômicos (universidade, exército, escritura, meios de comunicação); enfim, é objeto de debate político e de confronto social (as lutas "ideológicas")." In: FOUCAULT, M. Microfísica do Poder. 4. ed., Rio de Janeiro: Graal, 1984b. p. 12-13.

17 Hannah Arendt acredita que a verdade possa ser dividida em verdade factual e verdade filosófica. A factual tem o sujeito como contador da verdade e que tenta transformar o fato em opinião, ou seja, é imanentemente política, à medida que tenta transmitir fatos a uma platéia, “(...) relaciona-se sempre com outras pessoas; ela diz respeito a eventos e circunstâncias nas quais muito são envolvidos; é estabelecida por testemunhas e depende de comprovação; existe apenas na medida em que se fala sobre ela, mesmo quando ocorre no domínio da intimidade. É política por natureza". Contrapondo-se à verdade filosófica que é aquela em que "ao penetrar na praça pública, altera sua natureza e se torna opinião (...) uma modificação que não é meramente de uma espécie de raciocínio para outra, mas de um modo de existência humano para outro" In: ARENDT, Hannah. Entre o Passado e o Futuro. Trad. Mauro W. Barbosa. 6. ed., São Paulo: Perspectiva, 2009. p. 294-295. LAFER, Celso. A Mentira: um capítulo das relações entre a ética e a política. In: NOVAES, Adauto. Ética. São Paulo: Companhia das Letras, 1993. p. 225-237.
} 
agora foram incapazes de descobrir um substituto viável para substitui-la". Reforçando ainda que: "(...) a persuasão e a violência podem destruir a verdade, não substitui-la."

A condescendência com a mentira envenena a sociedade com hipocrisia, e por isso deve ser condenada socialmente, não se admitindo de forma alguma cumplicidade meramente omissa ou em troca de benefícios oportunistas. De todo modo não se vislumbra preocupação ou exigência em busca pela discriminação entre verdade e mentira, estando a verdade fadada a desaparecer do cenário da vida em sociedade, de modo que hoje a falsidade sequer representa constrangimento. ${ }^{19}$

O engano deliberado também é considerado uma mentira, que pode ser usada para manipular a sociedade, como ocorre em governos autoritários que almejem perpetuar como fonte única de poder, usando da mentira como seu instrumento de política. ${ }^{20} \mathrm{O}$ preocupante é que não apenas os Estados denominados autoritários estão fazendo uso dessa prática, artimanhas e estratégias de persuasão representam hoje, instrumentos absolutamente corriqueiros na condução da opinião pública.

Tendo a visibilidade se tornado o sintoma da conjuntura atual principalmente a partir da reprodutibilidade instantânea de informações desprovidas de qualquer averiguação e daquelas totalmente moldadas a interesses, transformou-se em nosso ambiente cognitivo.

Passando tudo a existir no exato instante de sua exposição, sem pressupor qualquer análise de conteúdo ${ }^{21}$ esquece-se da própria existência da verdade.

\footnotetext{
${ }^{18}$ ARENDT, Hannah. Entre o Passado e o Futuro. Trad. Mauro W. Barbosa. 6. ed., São Paulo: Perspectiva, 2009. p. 320.

${ }^{19}$ Nesse sentido Adorno reflete que: "A idéia de que o mundo quer ser enganado tornou-se mais verdadeira do que, sem dúvida, jamais pretendeu ser. Não somente os homens caem no logro, como se diz, desde que isso the dê uma satisfação por mais fugaz que seja, como também desejam essa impostura que eles próprios entrevêem; esforçam-se por fecharem os olhos e aprovam, numa espécie de autodesprezo, aquilo que lhes ocorre e do qual sabem por que é fabricado. Sem o confessar, pressentem que suas vidas se lhes tornam intoleráveis tão logo não mais se agarrem a satisfações que na realidade, não o são." In: ADORNO, T. W. A Indústria Cultural. FERNANDES, F. (Coord.) Sociologia. Grandes Cientistas Sociais, 54. São Paulo: Ática, 1986. p. 96.

${ }^{20}$ Arendt observa a esse respeito que: "O mentiroso tem a grande vantagem de saber de antemão o que a platéia deseja ou espera ouvir". In: ARENDT, Hannah. Crises da República. São Paulo: Perspectiva, 1973. p. 16.

${ }^{21}$ É possível crer em uma verdade única sob uma ótica kantiana, não conhecemos o limite que separa nossas estruturas cognitivas das propriedades do próprio objeto conhecido, o que significa que jamais conhecemos as coisas como elas realmente são, mas apenas como elas se apresentam, enquanto fenômenos, diante de nossas capacidades de apreensão. Questão que Platão já havia colocado em sua Teoria das Idéias, ao considerar que o mundo visível é composto de imagens que não nos oferece a essência das coisas, enquanto o mundo inteligível se encontra unicamente nas idéias, ou conceitos, das coisas, imperceptível aos nossos sentidos. In: PLATÃO. A República. Trad. de Eduardo Menezes. São Paulo: Hemus, 1970. p. 197.
} 
Observe-se os instrumentos midiáticos e sua tarefa de tornar visível tudo e todos, ultrapassando as barreiras do espaço e do tempo e da fidelidade dos próprios fatos reais noticiados. Frente a essa realidade desprovida de verdade, questiona-se, afinal a mídia reproduz ou produz informações? Ao que se entende que, a mídia deveria relatar acontecimentos e não criá-los e para tanto deveria pressupor verdade, realidade.

Nesse aporte, sempre tendo presente a necessidade de transparência nas relações, a discussão sobre mentira e segredo ${ }^{22}$ na vida pública se faz primordial, ao demonstrar que a falácia pode ser mais maléfica do que o próprio secreto, tão debatido anteriormente.

A imagem nem sempre corresponde à realidade, diante do conhecimento de que, nem sempre o que é tornado visível é verdadeiro. Baseado nesse cenário surge a preocupação de que a Constituição não deve atribuir legalidade ao poder arbitrário, ${ }^{23}$ para tanto a verdade é primordial.

Na medida em que se publiciza uma notícia a toda a coletividade, essa é tida como verdadeira, portanto legítima, assumindo concretude, desta monta, em sendo tal informação dotada de vícios, especialmente o da falsidade, estar-se-ía corrompendo toda a estrutura que legitimou tal mentira, que atribuiu força a um ato falacioso e arbitrário.

Embora se saiba que nem tudo que é verdadeiro é publicizado, a recíproca de que tudo que é publicizado seja verdadeiro deveria ser a regra, uma vez que é intolerável a notoriedade do falacioso, sendo a verdade um requisito indispensável à publicização para que então se faça uso da visibilidade do poder em favor do indivíduo e não contra ele ${ }^{24}$ não ficando a mercê das intenções que a publicidade, por vezes, oculta, para que realmente se possa falar em informação visível, impessoal, transparente e, portanto verdadeira.

E indo além, não apenas se deve preferir a visibilidade ao ocultamento em casos, fatos e informações verídicas, como também se torna imperativa, haja vista que, a verdade não pode ser negada, a verdade é memória, história. Não sendo possível a projeção de futuro ou sequer presente sem passado, como se irá aprender com os erros se eles permanecem no vazio da treva? ${ }^{25}$

\footnotetext{
${ }^{22}$ Para Hannah Arendt a mentira funciona como segredo, exemplificando sua posição, com o uso da mentira como artimanha para que os países poderosos continuem impondo sua hegemonia, utilizando-a para escamotear o arbítrio. In: ARENDT, Hannah. A Mentira Política: Considerações sobre os Documentos do Pentágono. In: Crises da República, (Crisis of the Republic). Coleção Debates. Trad. José Volkmasnn, Editora Perspectiva: São Paulo, 1973. p. 9-48.

${ }_{23}^{23}$ DALLARI, Dalmo de Abreu. Constituição e Constituinte. 2. ed., São Paulo: Saraiva, 1984.

${ }^{24}$ Nesse sentido DOTTI, René Ariel. Proteção da Vida Privada e Liberdade de Informação. Possibilidade e Limites. São Paulo: Editora Revista dos Tribunais, 1980. p. 191.

${ }^{25} \mathrm{~A}$ esse respeito ver o livro-relatório intitulado "Direito à verdade e à memória", que resgata um período fundamental da história do Brasil que trata dos casos de desaparecimentos e mortes de opositores políticos por autoridades do Estado durante o período 1961-1988, preconizando exatamente esse resgate à memória e à verdade que revela-se crucial tanto para o conhecimento
} 
Indubitavelmente o aporte ao direito de memória merece um estudo a parte em vista de sua inquestionável grandeza e extensão, não sendo pretensão do presente. Aqui cabe asseverar a cerca da necessidade de verdade, que demanda objetividade, impessoalidade e imparcialidade, ou seja, pressupõe um relato e não uma criação ${ }^{26}$ ou manipulação de dados e fatos.

Assim, de forma alguma se pretende desconsiderar a veracidade, apenas deve-se admiti-la como tal, ou seja, com um dos relatos de uma mesma realidade $^{27} \mathrm{e}$, portanto, deve-se oportunizar à coletividade o conhecimento do conteúdo narrado por seus diversos transmitentes, sendo inadmissível, portanto, a publicização da veracidade como retrato único de uma realidade, ou seja, como versão indiscutível. ${ }^{28}$

Desse modo, há de se ter em mente que não há produção de verdade, se isso ocorrer, com certeza não há verdade. E diante da ausência de verdade, do falacioso, do mentiroso, do duvidoso não há como falar em Administração Pública transparente e menos ainda em um Estado Democrático de Direito visível a todo o cidadão.

\section{REFERÊNCIAS BIBLIOGRÁFICAS}

ADORNO, T. W. A Indústria Cultural. FERNANDES, F. (Coord.) Sociologia. Grandes Cientistas Sociais, 54. São Paulo: Ática, 1986.

ARENDT, Hannah. A Mentira Política: Considerações sobre os Documentos do Pentágono. In: Crises da República, (Crisis of the Republic). Coleção Debates. Trad. José Volkmasnn, Editora Perspectiva: São Paulo, 1973.

de nossa história quanto para a projeção de um futuro melhor: "Redemocratizado, o Estado brasileiro cumpriu também um certo papel de juiz histórico ao fazer o resgate da memória e da verdade". In: BRASIL. Secretaria Especial dos Direitos Humanos. Comissão Especial sobre Mortos e Desaparecidos Políticos. Direito à Verdade e à Memória: Comissão Especial sobre Mortos e Desaparecidos. Brasília: Secretaria Especial dos Direitos Humanos, 2007. p. 18.

${ }^{26}$ A esse respeito de criação, manipulação da informação, ou seja, das mentiras habitualmente utilizadas na sociedade contemporânea Hannah Arendt conclui de forma trágica a inconsciência e a persistência destrutiva da mentira: " (...) a, longo prazo, o resultado mais certo da lavagem cerebral é uma curiosa espécie de cinismo - uma absoluta recusa a acreditar na verdade de qualquer coisa, por mais bem estabelecida que ela possa ser. Em outras palavras, o resultado de uma substituição coerente e total da verdade dos fatos por mentiras não é passarem estas a ser aceitas como verdade, e a verdade ser difamada como mentira, porém um processo de destruição do sentido diante o qual nos orientamos no mundo real - incluindo-se entre os meio mentais para esse fim a categoria de oposição entre verdade e mentira. [...] Esse é o motivo por que a mentira coerente, em termos metafóricos, arranca o chão de sob nossos pés, sem fornecer outra base em que nos postemos. In: ARENDT, Hannah. Entre o Passado e o Futuro. Trad. Mauro W. Barbosa de Almeida. 6. ed., São Paulo: Editora Perspectiva, 2009. p. 317-318.

${ }^{27}$ Não seria possível afirmar que a realidade seria o retrato da verdade?

${ }^{28}$ A busca pela verdade pode até nos parecer inatingível, todavia deve-se ter em mente que a realidade é concreta, e a verdade, portanto, não seria justamente o relato de realidade isento de quaisquer acréscimos? Além disso, sendo a veracidade uma versão da verdade, em se buscando versões de uma mesma realidade não se poderia alcançar a verdade? Assim, mostra-se possível a busca pela verdade, pois a legitimidade da veracidade pode trazer superficialidade não apenas à Administração Pública, mas a todo o Estado Democrático de Direito. O que se quer é que todas as veracidades possam vir a conhecimento do público para que então se viabilize a busca pela verdade. 
ARENDT, Hannah. Entre o Passado e o Futuro. Trad. Mauro W. Barbosa. 6. ed., São Paulo: Perspectiva, 2009.

ARENDT, Hannah. Crises da República. São Paulo: Perspectiva, 1973.

BRASIL. Secretaria Especial dos Direitos Humanos. Comissão Especial sobre Mortos e Desaparecidos Políticos. Direito à Verdade e à Memória: Comissão Especial sobre Mortos e Desaparecidos. Brasília: Secretaria Especial dos Direitos Humanos, 2007.

CARVALHO, Luiz Gustavo Grandinetti Castanho de. Liberdade de Informação e o Direito Difuso à Informação Verdadeira. 2. ed., Rio de Janeiro: Renovar, 2003.

DALLARI, Dalmo de Abreu. Constituição e Constituinte. 2. ed., São Paulo: Saraiva, 1984.

DOTTI, René Ariel. Proteção da Vida Privada e Liberdade de Informação. Possibilidade e Limites. São Paulo: Editora Revista dos Tribunais, 1980.

GADAMER, Hans-Georg. Verdade e Método II: complementos e índice. Tradução de Ênio Paulo Giachini. Petrópolis: Vozes, 2002.

FOUCAULT, M. Microfísica do Poder. 4. ed., Rio de Janeiro: Graal, 1984b.

HÄBERLE, Peter. Verdad y Estado Constitucional. 1. ed., México. D.F.: Instituto de Investigaciones Jurídicas, 2006.

LAFER, Celso. A Mentira: um capítulo das relações entre a ética e a política. In: NOVAES, Adauto. Ética. São Paulo: Companhia das Letras, 1993.

LIMBERGER, Têmis. O Direito à Intimidade na Era da Informática: A necessidade de proteção dos dados pessoais. Porto Alegre: Livraria do Advogado, 2007.

MARINONI, L. G.; ARENHART, S. A. Comentários ao Código de Processo Civil. 5 v. tomo 1. São Paulo: Revista dos Tribunais, 2000.

MENÉNDEZ, Ignácio Villaverde. Los Derechos Del Público: El derecho a recibir información del artículo 20.1.d) de la Constitución Española de 1978. Madrid: Editorial Tecnos S. A., 1995.

MIRANDA, Pontes de. Liberdade de Imprensa e Censura. In: BONAVIDES, Paulo. ET AL. As Tendências atuais do Direito Público: Estudos em homenagem ao professor Alfonso Arinos de Melo Franco. 1. ed., Rio de Janeiro: Forense, 1976.

NIETZSCHE, Friedrich. Sobre Verdade e Mentira. Fernando de Moraes Barros (Org. e Trad.) São Paulo: Hedra, 2007.

PLATÃO. A República. Trad. de Eduardo Menezes. São Paulo: Hemus, 1970.

STRECK, Lenio Luiz. Verdade e Consenso: Constituição, Hermenêutica e Teorias Discursivas. Da Possibilidade à Necessidade de Respostas Corretas em Direito. 2. ed., Rio de Janeiro: Lúmen Júris Editora, 2008.

TRIBE, Laurence e Michael Dorf. Hermenêutica Constitucional. Belo Horizonte: Editora Del Rey Ltda., 2007. 